\title{
Protective effects of calbindin-D28K on the UVB radiation-induced apoptosis of human lens epithelial cells
}

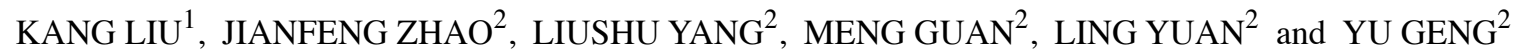 \\ ${ }^{1}$ Department of Ophthalmology, The 920th Hospital of The Joint Logistic Support Force; ${ }^{2}$ Department of Ophthalmology, \\ The First Affiliated Hospital of Kunming Medical University, Kunming, Yunnan 650031, P.R. China
}

Received October 17, 2019; Accepted March 13, 2020

DOI: $10.3892 / \mathrm{ijmm} .2020 .4552$

\begin{abstract}
Calbindin-D28K (Calb1) may protect human lens epithelial cells (HLECs) from apoptosis, which is a process resulting in individual cell death. The protective effects of Calb1 may be attributed to buffering high concentrations of $\mathrm{Ca}^{2+}$. The present study investigated the mechanisms through which Calb1 protects SRA01/04 cells (a human lens epithelial cell line) against apoptosis induced by ultraviolet B (UVB) exposure. Cells transfected with a lentivirus overexpressing Calb1 and control cells were treated with $40 \mu \mathrm{W} / \mathrm{cm}^{2}$ irradiation for $15 \mathrm{~min}$ and then cultured for $24 \mathrm{~h}$. The changes in intracellular $\mathrm{Ca}^{2+}$ were detected by colorimetry, and the protein expression levels of $\mathrm{Bad}, \mathrm{Bcl}-2$ and caspase-12 were measured by western blot analysis. The intracellular $\mathrm{Ca}^{2+}$ concentration of control HLECs increased significantly following UVB irradiation, whereas in Calb1-overexpressing cells, the $\mathrm{Ca}^{2+}$ levels remained steady. In the control cells, the expression of $\mathrm{Bad}$ and caspase-12 was upregulated, and that of Bcl-2 was downregulated. Notably, during UVB radiation-induced apoptosis, the overexpression of Calb1 inhibited cell death, resulting in the decreased expression of Bad and caspase-12, and in the upregulated expression of $\mathrm{Bcl}-2$. These results suggested that Calb1 inhibited the upregulation of genes involved in apoptosis. The siRNA-mediated knockdown of Calb1 resulted in increased rates of UVB radiation-induced apoptosis, the increased expression of Bad and caspase-12, and the decreased expression of Bcl-2, further demonstrating that Calb1 may mediate UVB radiation-mediated apoptosis by regulating $\mathrm{Ca}^{2+}$. On the whole, the findings of the present study indicate that UVB exposure can lead to an imbalance in the intracellular $\mathrm{Ca}^{2+}$ homeostasis in HLECs and that Calb1 protein exerts a negative effect on the expression of pro-apoptotic genes in
\end{abstract}

Correspondence to: Dr Yu Geng, Department of Ophthalmology, The First Affiliated Hospital of Kunming Medical University, 295 Xichang Road, Kunming, Yunnan 650031, P.R. China

E-mail: gengyu@mail2.sysu.edu.cn

Key words: calbindin-D28K, ultraviolet B, apoptosis, human lens epithelial cells
HLECs. Calb1 may thus inhibit the UVB radiation-induced apoptosis of HLECs by regulating $\mathrm{Ca}^{2+}$.

\section{Introduction}

Cataracts are one of the most common eye diseases and are a major cause of blindness worldwide. Ultraviolet radiation is a risk factor for cataract formation. Human lens epithelial cells (HLECs) are the most metabolically active cells in the lens, and they are also an important target tissue of ultraviolet (UV) radiation-induced damage, which is related to the occurrence and development of cataracts. The incidence of cataracts markedly increases at a certain dose of UV radiation to the lens. The UV radiation-induced apoptosis of HLECs is a common cytological cause of non-congenital cataract formation (1-3).

A number of studies have attempted to examine the effect of UV radiation on the human lens to determine the biochemical mechanisms through which ultraviolet B (UVB) irradiation induces cataract formation (4-7). UVB radiation is closely related to cataract formation, particularly in high elevation locations where individuals are subjected to increased exposure to UV radiation. Both human and animal studies have indicated that exposure to UVB causes cortical and posterior subcapsular cataracts (8-14). However, the exact association between UVB and HLECs has not yet been fully elucidated. UVB irradiation may induce cell apoptosis by activating the mitochondrial initiated programmed cell death pathway (15-17), which may be regulated by a variety of molecular processes. The mitochondria can rapidly lose their transmembrane potential and produce reactive oxygen species (ROS), both of which may contribute to cells breaking down (18).

Calbindin-D28K (Calb1) is a member of the $\mathrm{Ca}^{2+}$ binding protein family, whose members have the EF-hand structure domain $(19,20)$, and its molecular weight is approximately $28 \mathrm{kDa}(21)$. Calb1 is expressed in a number of organs and tissues, such as in brain (22), cerebellum (23), pancreatic (24), bone tissue $(25,26)$ and nervous system $(19,27)$. In a previous study by the authors it was found that Calb1 was also expressed in the lens of SD rats (28), and that it may play an important role in reducing and stabilizing the intracellular $\mathrm{Ca}^{2+}$ levels after the $\mathrm{Ca}^{2+}$ concentrations are increased in HLECs. It was hypothesized that Calb1 may exert protective effects on the lens in the presence of excess $\mathrm{Ca}^{2+}$-mediated damage to HLECs, induced 
by ionomycin. Calb1 may maintain calcium homeostasis by buffering excessive intracellular free $\mathrm{Ca}^{2+}$. The reduced protein and mRNA expression of Calb1 may lead to increased intracellular free $\mathrm{Ca}^{2+}$ concentrations that are observed in a number of age-related diseases (29-32). It has been indicated that Calb1 exerts neuroprotective effects on ischemic and glutamate toxicity models, which are primarily due to its ability to chelate $\mathrm{Ca}^{2+}(33-36)$. Calb1 can bind directly to caspase-3 in osteoblasts and inhibit its activity. Therefore, calbindin-D28K may prevent apoptosis through various mechanisms (37).

To verify the hypothesis that Calb1 participates in HLEC apoptosis and promotes HLEC survival, the present study examined the changes in $\mathrm{Ca}^{2+}$ levels during HLEC apoptosis induced by UVB and assessed the protective effects of Calb1.

\section{Materials and methods}

Cell culture and transfection. All experiments were conducted with the approval of the animal ethics committee of Kunming Medical University. The human lens epithelial cell line (HLECS-SRA01/04) was obtained from JCRB (the National Institute for Biomedical Innovation, NIBIO, Japan). All cultured cells were seeded at a density of $2 \times 10^{4}$ cells $/ \mathrm{ml}$ in 6 -well and/or 96-well plates that had been coated with poly-D-lysine and maintained in a $37^{\circ} \mathrm{C}, 5 \% \mathrm{CO}_{2}$ saturated humidity incubator. Cells were maintained in Dulbecco's modified Eagle medium (DMEM) with $10 \%$ heat-inactivated fetal bovine serum and $1 \%$ penicillin-streptomycin (Life Technologies; Thermo Fisher Scientific). When the SRA01/04 cells reached a density of $80 \%$, they were transported to 12 -well culture plates at a concentration of $2 \times 10^{5}$ cells per well in penicillin-streptomycin-free and serum-free medium or penicillin-streptomycin-free serum-free medium. The SRA01/04 cells were then transfected with lentiviruses (MOI=30) (GM easy TMLentiviral Packaging kit; cat. no. Gmeasy-10, Genomeditech) containing Calb1 cDNA or green fluorescent protein (GFP) cDNA; the obtained transduced cells are called SRA/Calb1 cells. Treatment with an siRNA (50 nM) (RiboBio) (Table I) was used to interfere with the expression of lentiviruses with the fluorescence microscope (BX51, Olympus Corp.) to further prove the protective effects of Calb1 against apoptosis.

Cell groups used in the present study. The cells were divided into 2 groups as follows: The SRA group (control SRA01/04 cells) and the SRA-Calb1 group (SRA/Calb1 cells stably overexpressing Calb1 due to treatment with lentiviruses). The cells were then further divided into 3 subgroups as follows: The control subgroup (without UVB irradiation or siRNA treatment), the UVB subgroup (with UVB irradiation) and the UVB + siRNA subgroup (with UVB irradiation and siRNA treatment). The SRA-control represented the control subgroup in the SRA group, SRA-UVB was the UVB subgroup in the SRA group, SRA-UVB-siRNA was the UVB + siRNA subgroup in the SRA group, SRA-Calb1 was the control subgroup in the SRA-Calb1 group, SRA-Calb1-UVB was the UVB subgroup in the SRA-Calb1 group, and SRA-Calb1-UVB-siRNA was the UVB + siRNA subgroup in the SRA-Calb1 group.

$U V B$ exposure. The UVB spectrum ranges from $280 \mathrm{~nm}$ to $320 \mathrm{~nm}$, and the peak irradiance is $300 \mathrm{~nm}$. In the present study,
UVB lamps (Sigma-Aldrich; Merck KGaA) were used for UV irradiation. The intensity of radioactivity was $40 \mu \mathrm{W} / \mathrm{cm}^{2}$, which was confirmed by a double-channel UVB illuminance meter (Shanghai Biaozhi Instrument Co., Ltd.). The exposure duration was $15 \mathrm{~min}$, and the radiant exposure was $36 \mathrm{~mJ} / \mathrm{cm}^{2}$, which was calculated by the following formula: $H=t \times E_{\ddot{e}}$ $\left[\mathrm{H}\right.$, radiant exposure $\left(\mathrm{J} / \mathrm{cm}^{2}\right) ; \mathrm{t}$, exposure duration $(\mathrm{sec}) ; \mathrm{E}_{\ddot{e}}$, measured irradiance $\left.\left(\mathrm{W} / \mathrm{cm}^{2}\right)\right]$ (38). All groups of irradiated cells were washed twice with phosphate-buffered saline (PBS, $\mathrm{pH} 7.4$ ) at $37^{\circ} \mathrm{C}$ to remove residual serum and unattached cells prior to UVB irradiation. Following UVB exposure, the culture medium was added to each well, and the cells were placed in incubators at $37^{\circ} \mathrm{C}$ and $5 \% \mathrm{CO}_{2}$ for $24 \mathrm{~h}$.

Cell counting kit-8 (CCK-8) cell viability assay. At $24 \mathrm{~h}$ following transfection and UVB irradiation, the cells were treated with CCK-8 (Dojindo Molecular Technologies, Inc.) in 96-well plates to evaluate cell viability. CCK-8 solution $(10 \mu \mathrm{l})$ was added to each well, and the cells were then placed in an incubator for $2 \mathrm{~h}$. The absorbance at $450 \mathrm{~nm}$ was determined by ELISA. The survival rate of each transfected cell group is shown as a percentage of the control group, which is set at $100 \%$.

Cytosolic $\mathrm{Ca}^{2+}$ measurement and $\mathrm{Ca}^{2+}$ concentration determination. Intracellular calcium levels were measured using a Fura-4/AM fluorescence indicator (Beyotime Institute of Biotechnology). Cells were grown in 6-well plates whose glass-bottom was coated with poly-D-lysine. They were then incubated with $5 \mu \mathrm{M}$ Fura-4/AM dissolved in Hank's balanced salt solution (HBSS) in which Pluronic F-127 (Beyotime Institute of Biotechnology) was added to a final concentration of $0.05 \%$. Cells were incubated for an additional $30 \mathrm{~min}$. Finally, the cells were imaged at room temperature using a Zeiss LSM 510 META confocal microscope at a wavelength of $488 \mathrm{~nm}$ (Carl Zeiss AG).

The concentration of intracellular calcium ions was determined by colorimetry (MAK022, Sigma-Aldrich; Merck KGaA). A $5 \mu \mathrm{M}(0.2 \mu \mathrm{g} / \mathrm{ml})$ CalciuStandard Solution (Sigma-Aldrich; Merck KGaA) was produced by the addition of $10 \mu \mathrm{l}$ of $500 \mu \mathrm{M}$ Calcium Standard Solution to $990 \mu \mathrm{l}$ water, and it was mixed with pipetting. Dilutions of the $5 \mu \mathrm{M}$ standard solution $(0,2,4,6,8$ and $10 \mu \mathrm{l})$ were added to a 96-well plate, in which an amount of water was added up to the volume of $50 \mu \mathrm{l}$ to generate 0 (assay blank), 0.4, 0.8, 1.2, 1.6 and $2.0 \mu \mathrm{g} /$ well standards, respectively. Cells in all groups cultured in the 6-well plate were washed with HBSS to remove residual serum and medium when cells reached $80 \%$ confluence. The cells were then placed on ice, and $200 \mu 1$ of water were added to the wells; subsequently, the cells were homogenized by ultrasonication. The homogenate was centrifuged at $16,097 \mathrm{x} \mathrm{g}$ for $15 \mathrm{~min}$ at $4^{\circ} \mathrm{C}$, and subsequently, $50 \mu \mathrm{l}$ of the supernatant was removed to test the $\mathrm{Ca}^{2+}$ concentration. A total of $90 \mu \mathrm{l}$ of chromogenic reagent (MAK022, Sigma-Aldrich; Merck KGaA) was added to each well containing standards and was gently mixed. Subsequently, $60 \mu \mathrm{l}$ of Calcium Assay Buffer (MAK022, Sigma-Aldrich) were added to each well and gently mixed. The cells were then incubated for 5-10 min at room temperature, and the plate was shielded from light during incubation. The intracellular $\mathrm{Ca}^{2+}$ concentration was 
Table I. The constructed siRNA sequence.

Position SS sequence $\quad$ AS sequence
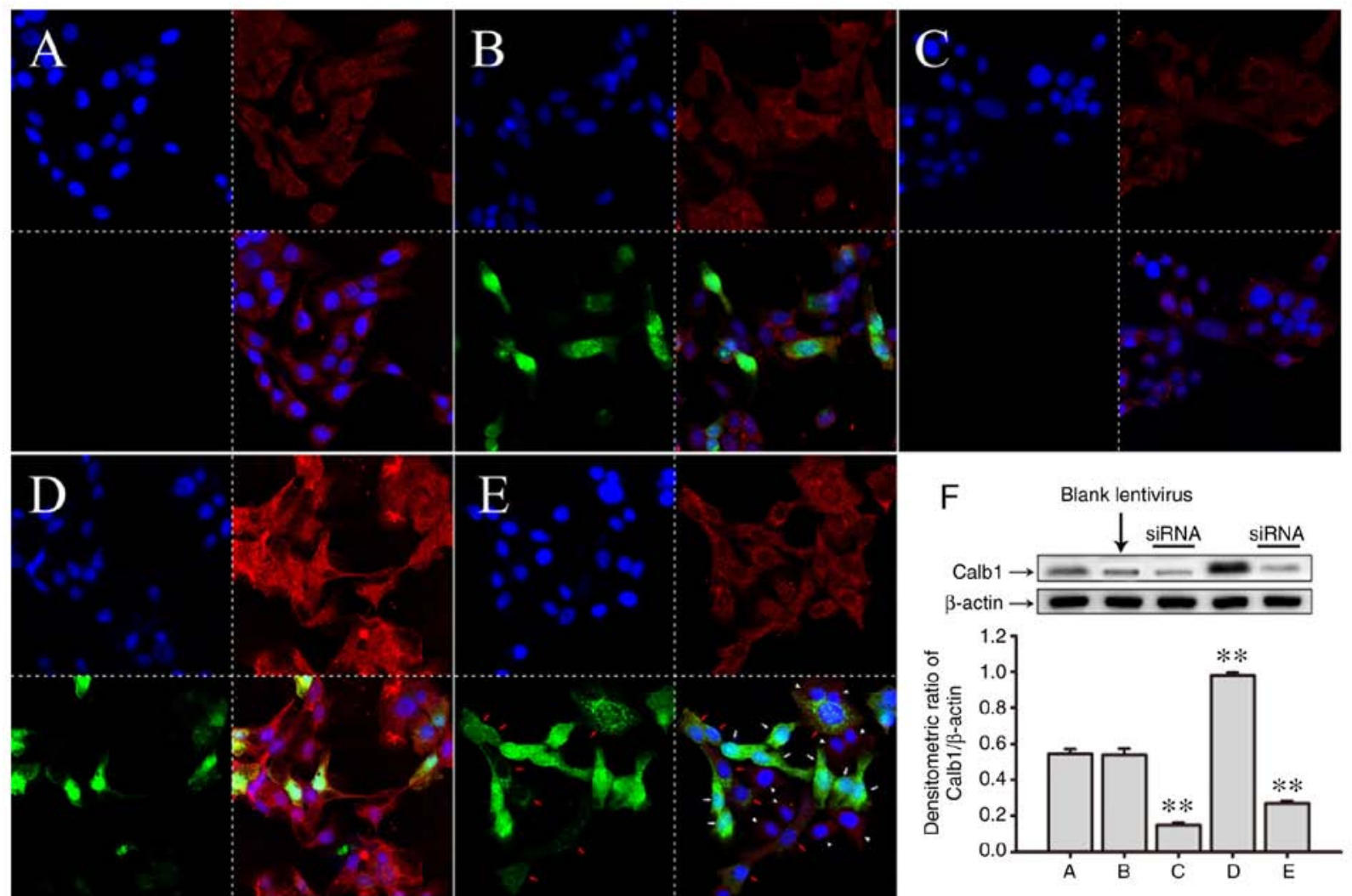

Figure 1. Immunofluorescent staining of SRA01/04 cells transfected with a lentivirus carrying Calb1 cDNA. In each image in (A-E) the top left image $r$ the cell nucleus, the top right shows the Calb1 protein, the bottom left shows the GFP and the bottom right shows the merged image, respectively. (A) Control SRA01/04 cells. Calb1 expression was granular (red fluorescence). (B) SRA01/04 cells transfected with empty lentiviral vectors carrying green fluorescent protein (GFP). Cells were successfully transfected. (C) SRA01/04 cells after siRNA-mediated Calb1 knockdown. The expression and distribution of Calb1 is shown. SRA01/04 cells exhibited significantly less Calb1 following siRNA transfection. (D) SRA01/04 cells transfected with lentiviral vectors carrying Calb1 cDNA and green fluorescent protein (GFP). These cells overexpressed Calb1 protein (red fluorescence). (E) Calb1-overexpressing SRA01/04 cells were treated with the siRNA. The expression of Calb1 was significantly reduced. (F) Quantitative analysis of Calb1 protein expression in the above-mentioned groups western blot analysis. Compared with the control group, there was no significant change in Calb1 expression in the groups transfected with an empty lentivirus $(\mathrm{P}>0.05)$; however, the significant overexpression of Calb1 was observed in the groups transfected with lentivirus carrying the Calb1 cDNA $\left({ }^{* *} \mathrm{P}<0.01\right)$. In addition, transfection with siRNA significantly decreased the levels of Calbl $\left.{ }^{* *} \mathrm{P}<0.01\right), \mathrm{n}=8$. Calb1, calbindin-D28K. White arrows, completely transfected cells; red arrows, incompletely transfected cells; white arrowhead, untransfected cells.

calculated using the following formula: $\mathrm{C}_{\mathrm{Ca}}=\mathrm{Sa} / \mathrm{Sv}\left[\mathrm{C}_{\mathrm{Ca}}\right.$, concentration of calcium in the sample; $\mathrm{Sa}$, amount of calcium in unknown sample $(\mu \mathrm{g})$ from standard curve; Sv, sample volume $(\mu \mathrm{l})$ added into the wells; calcium molecular weight, $40 \mu \mathrm{g} / \mu \mathrm{mol}]$.

Annexin V/PI staining. Annexin V-FITC/PI staining and flow cytometry were used to investigate the effects of UVB irradiation on the apoptosis of treated cells. Flow cytometric analysis was performed using Annexin ${ }^{+} / \mathrm{PI}^{-}$, Annexin ${ }^{+} / \mathrm{PI}^{+}$, Annexin $/ \mathrm{PI}^{+}$, and unlabeled cells (Annexin $\left./ \mathrm{PI}^{-}\right)$. Cells were labeled with Annexin V-FITC and propidium iodide (PI) (Annexin V-FITC apoptosis assay kit, Dojindo Molecular Technologies, Inc.). A total of $1 \times 10^{5}$ cells $/ \mathrm{ml}$ experimental cells were seeded in 6-well plates for $48 \mathrm{~h}$, washed with $37^{\circ} \mathrm{C}$ PBS (pH 7.4), exposed to $400 \mu \mathrm{W} / \mathrm{cm}^{2} \mathrm{UVB}$ radiation for $15 \mathrm{~min}$ and incubated in a $5 \% \mathrm{CO}_{2}$ incubator for $48 \mathrm{~h}$. Adherent cells were washed with $37^{\circ} \mathrm{C}$ sterile PBS 3 times and digested by treatment with $0.5 \%$ pancreatic enzyme for $5 \mathrm{~min}$. Subsequently, a $1 \times 10^{6}$ cell $/ \mathrm{ml}$ cell suspension was prepared in Annexin $\mathrm{V}$ binding solution after the pancreatic enzyme was inactivated by the addition of fetal bovine serum. A $100 \mu \mathrm{l}$ suspension of cells was added to $5 \mu \mathrm{l}$ of Annexin V-FITC and $5 \mu \mathrm{l}$ of PI, and the solution was incubated at room temperature for $15 \mathrm{~min}$, while keeping the solution out of light. A total of $400 \mu 1$ of Annexin $\mathrm{V}$ Binding solution was then added for flow cytometric analysis (Accuri C6 flow cytometer, BD Biosciences). The data collected in each window were designated as the FL-1 channel and FL-2 channel. The unlabeled cells, the cells labeled with only Annexin, and the cells labeled 


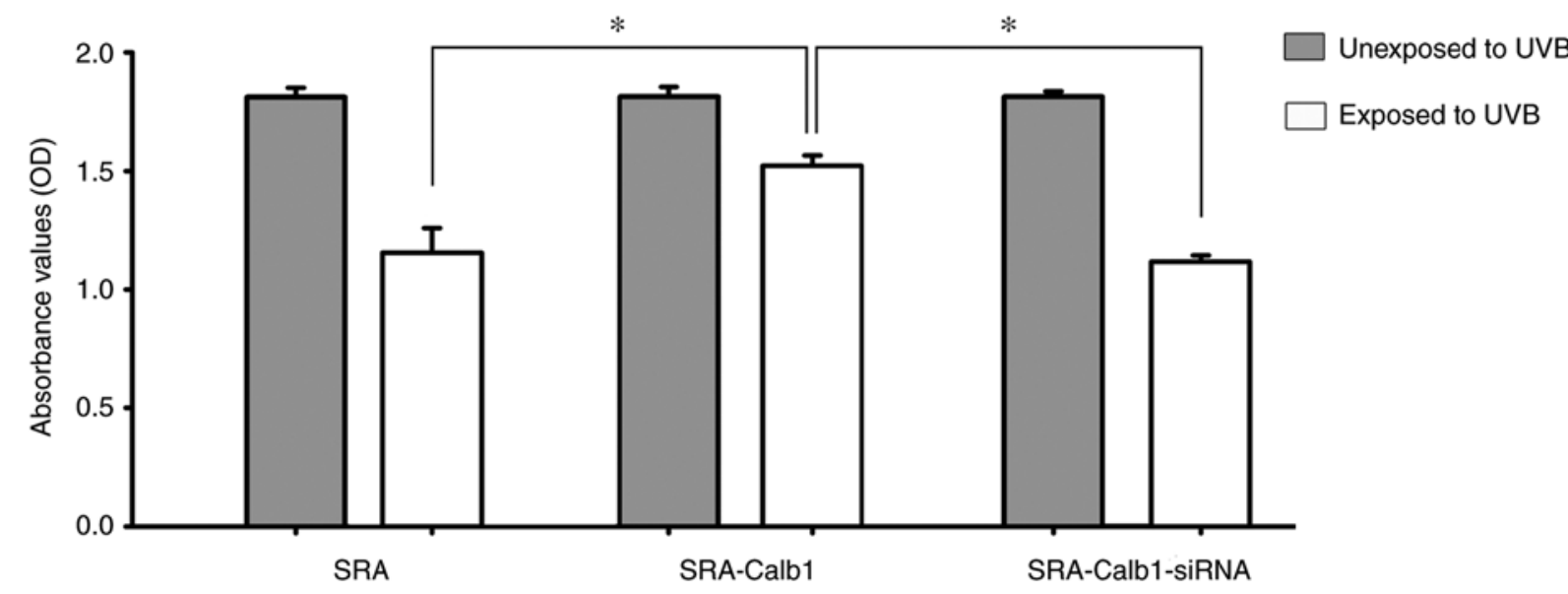

Figure 2. Cell viability assay. The absorbance values of control SRA01/04 cells (unexposed to UVB radiation) exhibited no significant change in cell viability among the 3 groups, which suggested that their viability was not affected by lentiviral transfection or siRNA treatment. The absorbance values of the SRA01/04 cells irradiated with UVB at $40 \mu \mathrm{W} / \mathrm{cm}^{2}$ for $15 \mathrm{~min}$ at $24 \mathrm{~h}$ are displayed as white bars. This result suggested that the viability of SRA01/04 cells overexpressing Calb1 was significantly higher than that of the control group and the siRNA treatment group ( $\mathrm{P}<0.05), \mathrm{n}=8$. Calb1, calbindin-D28K.

with only PI were used as controls to regulate the compensation between the flow cytometry and the detector, which then allowed the quadrants to be set. Analysis was performed on $1 \times 10^{4}$ cells per sample.

Western blot analysis. Under the same experimental conditions, cells in each group were used for protein quantification by western blot analysis. Experimental cells were washed with ice-cold PBS and lysed for $10 \mathrm{~min}$ in a buffer containing $50 \mathrm{mM}$ Tris (pH 7.0), 2 mM EDTA, $1 \%$ Triton X-100, $2 \mathrm{mM}$ PMSF, and $10 \mu \mathrm{g} / \mathrm{ml}$ leupeptin and aprotinin. The cell lysate was centrifuged at $13,000 \mathrm{x}$ g for $15 \mathrm{~min}$ at $4^{\circ} \mathrm{C}$. The protein concentration of the supernatant was measured using a microvolume UV-Vis spectrophotometer (NanoDrop 2000, Thermo Fisher Scientific, Inc.). A total of $20 \mu \mathrm{g}$ of protein from each sample was separated by $10 \%$ SDS-PAGE. The proteins were then transferred onto polyvinylidene fluoride (PVDF) membranes (Bio-Rad Laboratories, Inc.). The membranes were incubated overnight at $4^{\circ} \mathrm{C}$ with the following primary antibodies: Rabbit anti-polyclonal Calb1 (1:3,000, cat. no. C253L-100ULCN, Merck KGaA), rabbit anti-cleavage products of caspase-12 (1:1,000, cat. no. ab62484, Abcam), rabbit anti-Bad (1:1,000, cat. no. ab32445, Abcam), rabbit anti-Bcl-2 (1:1,000, cat. no. ab32124, Abcam) and rabbit anti-monoclonal $\beta$-actin (1:1,000, cat. no. ab115777, Abcam). Subsequently, the membranes were washed and incubated with the appropriate HRP-conjugated secondary antibodies $(1: 2,000$, cat. no. ab7090, Abcam) at room temperature for $60 \mathrm{~min}$, and specific bands in the membranes were detected using enhanced chemiluminescence (ECL, CWBio). Background samples from an area near each lane were subtracted from each band to obtain a mean band density. Densitometric ratios (ChemiDoc $^{\mathrm{TM}}$ XRS+, Bio-Rad Laboratories, Inc.) between CALB1 and $\beta$-actin were calculated to determine the relative levels of these proteins.

Statistical analysis. All experiments were repeated 3 times, and average values were obtained. The data were analyzed for significance using repeated measures, and the data were analyzed using one-way ANOVA of variance with the Student-Newman-Keuls post hoc test. All values are represented as the means $\pm S D$, and values of $\mathrm{P}<0.05$ or $\mathrm{P}<0.01$ were considered to indicate statistically significant and highly statistically significant differences, respectively.

\section{Results}

SRA01/04 cell transfection with Calblexpression vectors. Both SRA01/04 parental cells and SRA/Calb1 cells express detectable levels of endogenous Calb1 protein. To confirm that cells were transfected, SRA01/04 cells were treated with a lentivirus containing GFP cDNA as an indicator. Subsequently, the cells in a single field were examined under a fluorescence microscope. The expression of GFP in the SRA01/04 cells indicated that the lentivirus carrying Calb1 cDNA was successfully transfected into the target cells (Fig. 1).

To further confirm the success of transfection in these cells, western blot analysis was performed to measure the expression level of Calb1. The expression of Cabl1 in the SRA01/04 cells transfected with the Calb1-cDNA vector was higher than that of the SRA01/04 cells transfected with a blank lentivirus vector (Fig. 1D and F).

In the experiment, lentivirus was added to the culture plate to transfect the SRA01/04 cells which were marked with GFP, and there is no marker to indicate the interfered cells by siRNA. As shown in Fig. 1E, it can be seen that there are 8 cells which were evidently transfected with lentivirus (green fluorescence inside the cytoplasm, white arrows), 7 cells which were transfected incompletely (cytoplasm with dotted green fluorescence with a red Calb1 expression dot, red arrows), and there were 9 cells not transfected (no green fluorescence, and only Calb1 red fluorescence expression in the cytoplasm, white arrowhead). It was noted that there was almost no expression of Calb1 (red fluorescence) in the cytoplasm of the cells that were successfully transfected with lentivirus, and the expression intensity of Calb1 (red fluorescence) in the cells that were not thoroughly transfected and those that were not successfully transfected was superficially the same as that in the control 

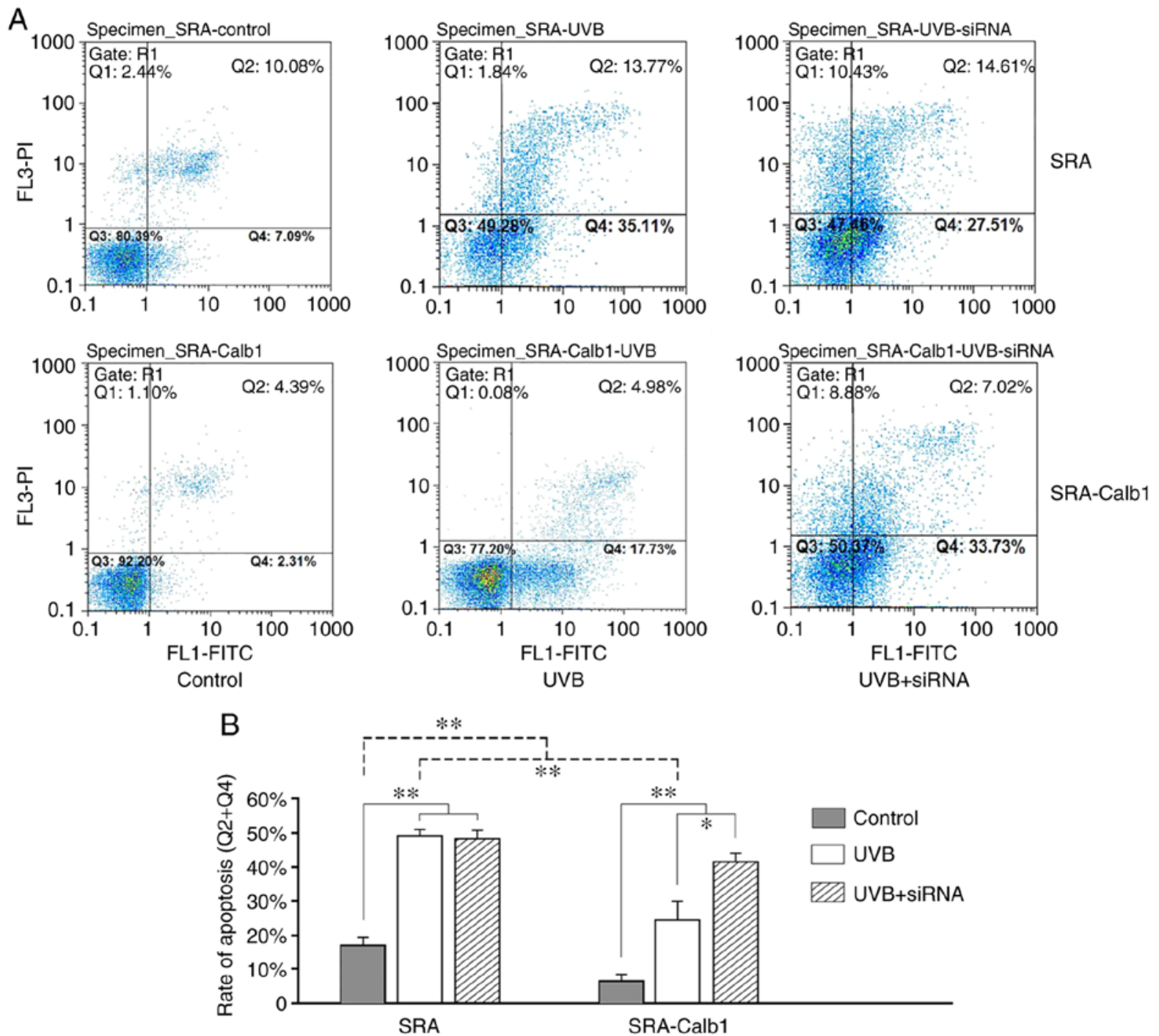

Figure 3. Annexin V/PI flow cytometric apoptosis assay. There were 2 groups: The SRA (control SRA01/04 cells) and the SRA-Calb1 group (SRA/Calb1 cells stably overexpressing Calb1 due to treatment with lentiviruses), and each group was subsequently divided into several subgroups: Control group (intact cells), UVB group (UVB irradiation) and UVB + siRNA group (UVB irradiation following siRNA interference). Each experiment was repeated 3 times, and 8 samples in the same subgroup were detected in one experiment. (A) There was a result of one representative experiment of each group. The rate of apoptosis in the UVB and UVB + siRNA subgroups of the SRA group and the UVB + siRNA subgroup of the SRA-Calb1 group (irradiated by UVB with $40 \mu$ W/cm ${ }^{2}$ for $15 \mathrm{~min}$ ) increased significantly in the early (Q4) and late (Q2) stages. (B) Comparison of the average apoptosis rates for the early and late stages among the groups. In the SRA group, the same average apoptosis rate was observed in the UVB and UVB + siRNA subgroups, both of which were higher than that of the control group $(\mathrm{P}<0.01)$. Comparing subgroups within the SRA-Calb1 group, the average apoptosis rate in the UVB subgroup was significantly lower than that of the UVB + siRNA subgroup $(\mathrm{P}<0.05)$ and was significantly higher that of the control subgroup $(\mathrm{P}<0.01)$. Compared with the SRA group, the average apoptosis rate of UVB subgroup of the SRA-Calb1 group was significantly lower than that of the UVB and UVB + siRNA subgroups of the SRA group $(\mathrm{P}<0.01), \mathrm{n}=8$. Calb1, calbindin-D28K. ${ }^{*} \mathrm{P}<0.05 ;{ }^{* * *} \mathrm{P}<0.01$.

group. However, the expression intensity of Calb1 in all cells shown in Fig. 1E was significantly decreased compared with that of the cells shown in Fig. 1D. Therefore, in Fig. 1E, the expression of Calb1 in the lentivirus-transfected cells exhibited an 'all-or-none' phenomenon, that is, the transfected cells exhibited an expression, whereas the untransfected cells did not exhibit an expression. Thus, the total expression of Calb1 protein in all cultured cells was lower than that in the control group following the quantification of the western blots.

CCK-8 proliferation assay. At $24 \mathrm{~h}$ following irradiation with $40 \mu \mathrm{W} / \mathrm{cm}^{2}$ of UVB, the SRA01/04 cells were transfected with a lentivirus and a siRNA. Compared with the control group, no significant change was observed in the proliferation of the SRA01/04 cells in groups that were not exposed to UVB, regardless of lentivirus transfection or siRNA knockdown. Following UVB irradiation, the proliferation of the SRA01/04 cells overexpressing Calbl protein was significantly higher than that of the control group and the siRNA interference group (Fig. 2).

UVB-induced apoptosis detected by flow cytometry. UVB is known to induce the apoptosis of HLECs $(39,40)$. Fig. 3A only shows the result of one representative experiment from each group. Each experiment was repeated 3 times, and 8 samples in the same subgroup were detected in one experiment. Fig. 3B illustrates the average apoptotic rate of each group. The average rate of apoptosis in the SRA group at $24 \mathrm{~h}$ 

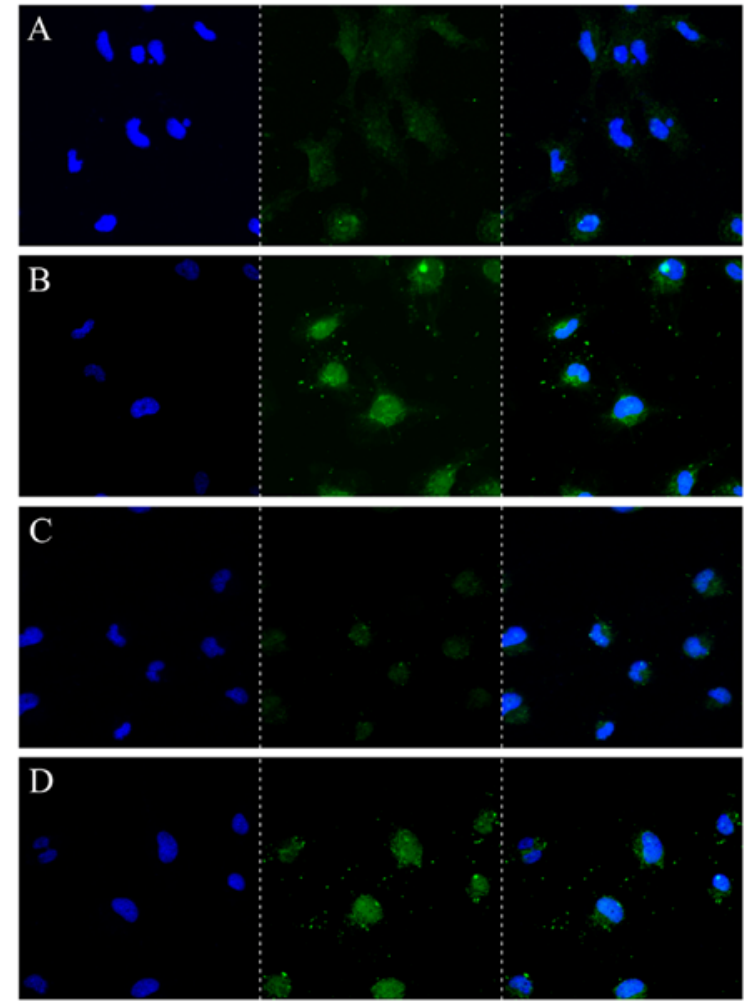

$E$

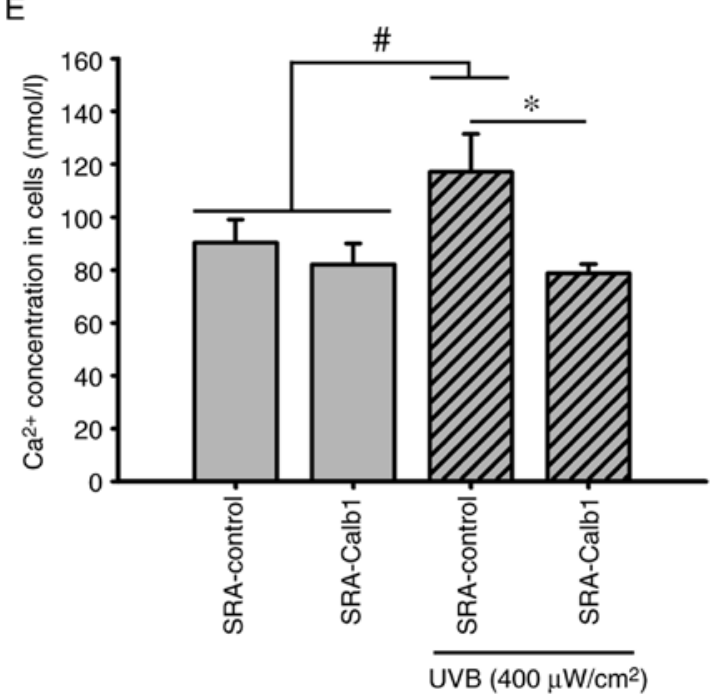

Figure 4. Intracellular calcium concentration assay. In each of the images in (A-D) the left image shows the cell nucleus, the center shows the intracellular $\mathrm{Ca} 2+$ and the right shows the merged image, respectively. (A) Control SRA01/04 cells with diffuse $\mathrm{Ca}^{2+}$ distribution. (B) Control SRA01/04 cells after UVB irradiation. The green granules show the distribution of intracellular $\mathrm{Ca}^{2+}$; the concentration of intracellular $\mathrm{Ca}^{2+}$ was significantly increased following UVB irradiation $[(\mathrm{P}<0.05)(\mathrm{E})]$. (C) SRA01/04 cells overexpressing Calb1. There was no significant difference in $\mathrm{Ca}^{2+}$ concentration in the Calb1 overexpressing cells compared with the control SRA01/04 cells $[(\mathrm{P}<0.05)(\mathrm{E})]$. (D) SRA01/04 cells overexpressing calb1 and expose to irradiation with UVB. The intracellular $\mathrm{Ca}^{2+}$ concentration was significantly lower than that of the control SRA01/04 cells following UVB irradiation $(\mathrm{P}<0.05)$. The intracellular $\mathrm{Ca}^{2+}$ concentration of SRA01/04 cells overexpressing Calb1 was not altered following UVB irradiation $(\mathrm{P}>0.05) . \mathrm{n}=8$. Calb1, calbindin-D28K. ${ }^{*, \#} \mathrm{P}<0.05$.

was $16.89 \pm 2.41 \%$ in the control subgroup, $49.42 \pm 2.07 \%$ in the UVB subgroup and $48.06 \pm 3.17 \%$ in the UVB + siRNA subgroup, while the comparable results in the SRA-Calb1 group were $7.18 \pm 1.80 \%$ in the control subgroup, $25.64 \pm 4.33 \%$ in the UVB subgroup and $42.03 \pm 2.57 \%$ in the UVB + siRNA subgroup, respectively. The rate of apoptosis in the SRA-Calb1 group was low in all subgroups except for the UVB + siRNA subgroup. The survival of cells treated with $40 \mu \mathrm{W} / \mathrm{cm}^{2} \mathrm{UVB}$ in the SRA group was decreased by approximately $32-77 \%$ at $24 \mathrm{~h}$ compared to the control cells (Fig. 3). The function of Calb1 was investigated by inducing its overexpression and knockdown in SRA01/04 cells. Transfection with a Calb1 expression vector resulted in a significant increase in cell survival following exposure to UVB after $24 \mathrm{~h}$ (Fig. 3). The siRNA-mediated inhibition of Calb1 expression significantly decreased cell survival following exposure to UVB after $24 \mathrm{~h}$ (Fig. 3). These results indicate that UVB-induced apoptosis is regulated by the expression of Calb1.

The inhibition of cell apoptosis is not equal to the increase in cell proliferative activity. As shown in Fig. 2, the cell proliferative activity of the cells in the control group, which were transfected with lentivirus overexpressing Calb1, indicated that the transfection with lentivirus did not affect SRA01/4 cell viability. As shown in Fig. 3, the decrease in the apoptotic rate of the cells in the control group, which were transfected with lentivirus overexpressing Calb1, indicated that Calb1 could only exert an inhibitory effect on apoptosis, whereas this does not indicate that the inhibition of apoptosis can increase cell viability.

Intracellular $\mathrm{Ca}^{2+}$ distribution and concentrations. The Fluo-4AM Ca ${ }^{2+}$ fluorescence probe was used to identify changes in the distribution of $\mathrm{Ca}^{2+}$ in SRA01/04 cells in vitro. Compared with the control group, the intracellular concentrations of $\mathrm{Ca}^{2+}$ in the untransfected groups with UVB irradiation treatment were increased at $48 \mathrm{~h}$, and in the SRA01/04 cells overexpressing Calb1, a stable $\mathrm{Ca}^{2+}$ distribution and concentrations at $48 \mathrm{~h}$ following UVB irradiation were found (Fig. 4E). In the present study, the intracellular $\mathrm{Ca}^{2+}$ concentration was approximately $90.39 \pm 8.71 \mathrm{nmol} / \mathrm{l}$ (Fig. 4E) in the SRA-control group and approximately $117.12 \pm 14.39 \mathrm{nmol} / \mathrm{l}$ (Fig. 4E) in the group of untransfected cells irradiated with UVB. The SRA01/04 cells overexpressing Calb1 were irradiated with UVB for $24 \mathrm{~h}$, and the intracellular $\mathrm{Ca}^{2+}$ concentration was maintained at $78.68 \pm 3.53 \mathrm{nmol} / \mathrm{l}$ (Fig. 4E). The intracellular $\mathrm{Ca}^{2+}$ concentration in SRA 01/04 cells, which overexpressed Calb1 and not to be exposed to UVB, was $82.02 \pm 7.98 \mathrm{nmol} / 1$ (Fig. 4E).

UVB-induced apoptosis is associated with Bad, Bcl-2 and caspase-12 expression. UVB-induced apoptosis is associated with the expression of the apoptotic proteins, Bad, Bcl-2 and caspase-12; thus, in the present study, the expression levels of these proteins were examined by western blot analysis. In the control group of untransfected lens epithelial cells, a significant increase in Bad and caspase-12 protein expression was observed at $24 \mathrm{~h}$ following UVB irradiation for $15 \mathrm{~min}$ (Fig. 5A, B and D). Bcl-2 protein expression was significantly decreased at the same time point (Fig. 5A and C). Following exposure to UVB, the group of SRA01/04 cells that were transfected with the Calb1 overexpression vector exhibited a significant downregulation in the protein expression of $\mathrm{Bad}$ compared to the untransfected cells, while the expression of 
A
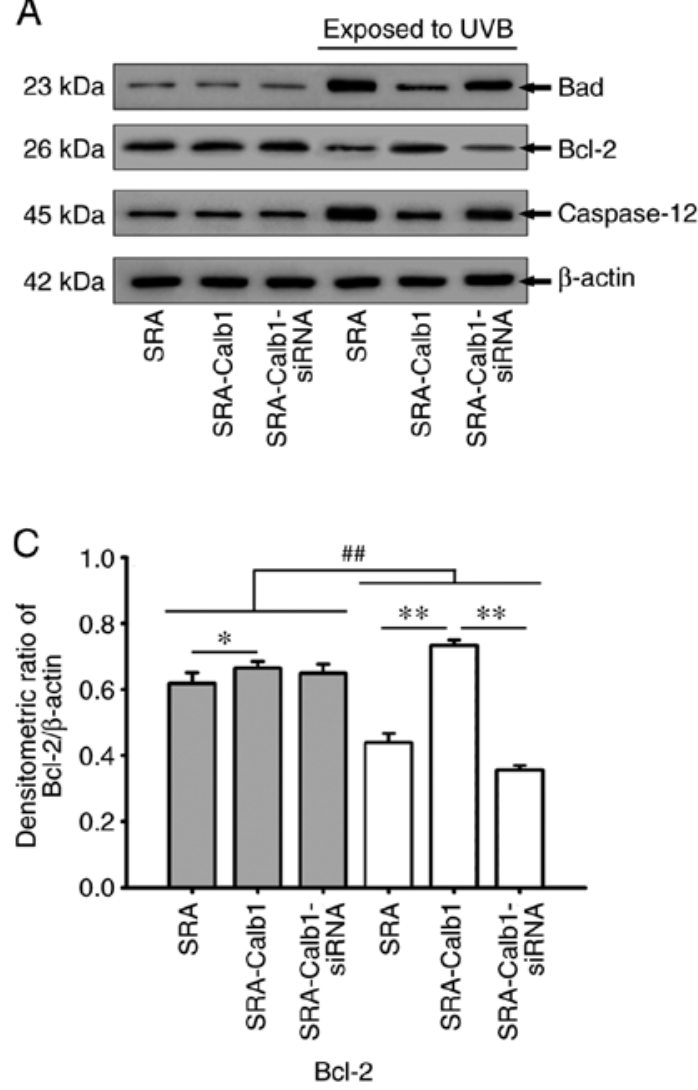

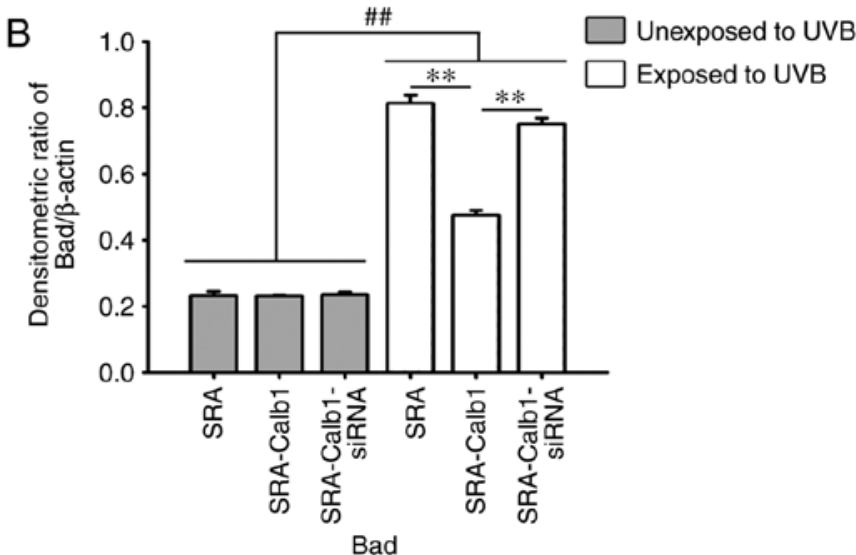

$\mathrm{D}$

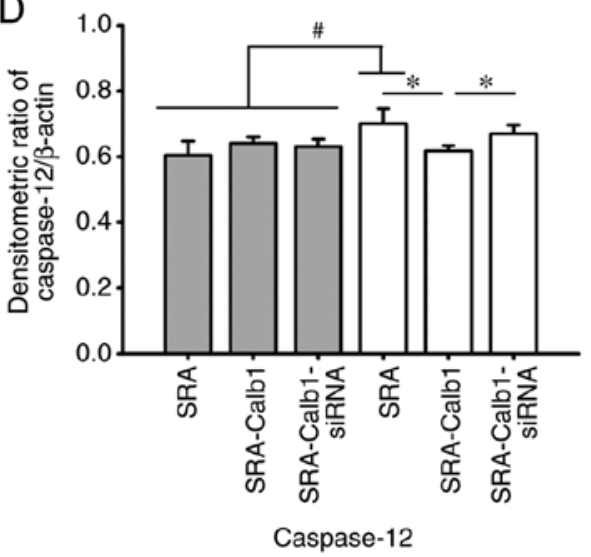

Figure 5. Western blot analysis. The expression levels of Bad, Bcl-2 and caspase-12 in control SRA01/04 cells and SRA01/04 cells overexpressing Calb1 after UVB irradiation are shown. (A) Western blot signals for Bad (23 kDa), Bcl-2 (26 kDa), caspase-12 (45 kDa) and internal control $\beta$-actin (42 kDa). (B) Changes in Bad protein expression in control SRA01/04 cells and cells overexpressing Calb1. Compared with cells not exposed to UVB irradiation, Bad protein expression levels after UVB irradiation was significantly increased $(\mathrm{P}<0.01)$. Bad protein expression in cells overexpressing Calb1 was significantly lower than that in the control SRA01/04 cells and in cells transfected with the siRNA (P<0.01). (C) Change of the Bcl-2 protein expression level. Compared with cells not exposed to UVB irradiation, Bcl-2 protein in cells after UVB irradiation was significantly downregulated in control SRA01/04 cells and cells overexpressing Calb1 that were also treated with the siRNA $(\mathrm{P}<0.01)$, while it was upregulated in cells overexpressing Calb1 ( $<0.05)$. However, in cells exposed to UVB irradiation, the Bcl-2 protein expression in the cells overexpressing Calb1 was significantly higher than it was in normal SRA01/04 cells and cells overexpressing Calb1 that were also treated with the siRNA $(\mathrm{P}<0.01)$. (D) Changes in caspase-12 protein expression levels. Compared with cells that were not exposed to UVB irradiation, the expression of caspase-12 protein in cells that were exposed to UVB irradiation was upregulated in control SRA01/04 cells $(\mathrm{P}<0.05)$, while the expression of caspase-12 in cells overexpressing Calb1 and the siRNA interference group was not significantly changed. In the cells exposed to UVB irradiation, the expression of caspase-12 in the cells overexpressing Calb1 was lower than it was in the other two groups $(\mathrm{P}<0.05)$. $\mathrm{n}=8$. Calb1, calbindin-D28K. ${ }^{*, \#} \mathrm{P}<0.05 ;{ }^{* *, \# \#} \mathrm{P}<0.01$.

Bcl-2 protein was significantly upregulated (Fig. 5A, B and C). Bcl-2 is an inhibitory apoptotic protein, and it can play an anti-apoptotic role through the inhibition of the $\mathrm{Ca}^{2+}$ flow crossing the cell membrane, consequently regulating the intracellular $\mathrm{Ca}^{2+}$ concentration. This is consistent with results of flow cytometric analysis illustrated in Fig. 3. However, the expression of caspase-12 did not differ significantly from that of the control group in which the cells were unexposed to UVB (grey bars) at the same time point (Fig. 5A and D).

The knockdown of Cabll expression increased UVB-induced apoptosis. Calbl protein was knocked down by siRNA transfection to examine the effects of its downregulation on the apoptosis of SRA01/04 cells. The cells transfected with siRNA downregulated Calb1 expression in the SRA01/04 cells, and this was confirmed by western blot analysis (Fig. 1F). Compared with the SRA01/04 cell control groups, the protein expression of Bad was upregulated following UVB irradiation and treatment with siRNA to downregulate Calb1; however, $\mathrm{Bcl}-2$ expression was downregulated under the same conditions
(Fig. 5A, B and C). The expression of the Caspase-12 protein did not change. These results suggest that Calb1 may play a protective role in UVB-mediated HLEC death.

\section{Discussion}

HLECs grow in a monolayer under the anterior subcapsular surface of the lens. As the cornea and aqueous humor do not filter UV light, the HLECs can be exposed to UVB radiation. There is some evidence to indicate that UV-induced cataract formation is caused by damage to the HLECs $(14,41,42)$. The apoptosis of HLECs is a common cellular basis for non-congenital cataract formation in humans and animals (3). UVB exhibits strong radiation energy, and it has the ability to penetrate tissues and damage cells. Studies have shown that UV-induced cell damage of lens epithelial cells is strongest at $297 \mathrm{~nm}$, which is in the UVB range (43). The lens contains two types of cells: Lens epithelial cells with $\mathrm{Ca}^{2+}$ pumps in the membranes and lens fiber cells without $\mathrm{Ca}^{2+}$ 
pumps (44). Therefore, $\mathrm{Ca}^{2+}$ homeostasis in the lens is solely dependent on lens epithelial cells. Cell membrane calcium ATPase is a high affinity $\mathrm{Ca}^{2+}$ pump. It uses the energy produced by ATP hydrolysis to transport $\mathrm{Ca}^{2+}$ from inside to outside cells to maintain the electrochemical gradient of cells (44). The pump also plays an important role in cell calcium homeostasis and signal transduction. There are four subtypes of cell membrane calcium ATPases: 1-4. All four subtypes are expressed in human lens epithelial cells (45). A previous study found that UVB irradiation can increase intracellular $\mathrm{Ca}^{2+}$ levels, inhibit $\mathrm{Ca}^{2+}$-ATPase activity and downregulate PMCA1 expression at the mRNA and protein levels. These findings reveal that the downregulation of cell membrane calcium ATPase1 levels and the loss of calcium homeostasis may play important roles in UVB-induced apoptosis following UVB irradiation (46). UVB irradiation induces cell death by activating the apoptotic pathway initiated by mitochondria (15). UVB radiation-induced apoptosis is regulated by various molecular processes. Mitochondria rapidly lose transmembrane potential and produce reactive oxygen species (ROS), and both results may contribute to the breakdown of cells (18). The concentration of free intracellular $\mathrm{Ca}^{2+}$ is maintained at a relatively low level to ensure normal physiological cell function. Studies have shown that the level of $\mathrm{Ca}^{2+}$ in HLECs is approximately $78 \pm 33 \mathrm{nmol} / \mathrm{l}$ or $96 \pm 20 \mathrm{nmol} / \mathrm{l}(47,48)$. Previous studies have found that UVB irradiation can apparently increase intracellular $\mathrm{Ca}^{2+}$ levels $(49,50)$, and the present study also revealed that an elevation in intracellular $\mathrm{Ca}^{2+}$ levels occurred following UVB irradiation. Further, we found that SRA01/04 cells overexpressing Calb1 can effectively prevent the increase of $\mathrm{Ca}^{2+}$ concentration after UVB irradiation. The results of the present study demonstrated that UVB irradiation with $40 \mu \mathrm{W} / \mathrm{cm}^{2}$ for 15 min significantly induced the of apoptosis of SRA01/04 cells, which was accompanied by a significant increase in the concentration of $\mathrm{Ca}^{2+}$ in these cells. The intensity of UVB irradiation with approximately $40 \mu \mathrm{W} / \mathrm{cm}^{2}$ is known as the appropriate concentration to affect HLEC apoptosis (16). In HLECs, intracellular $\mathrm{Ca}^{2+}$ homeostasis is a necessary condition to maintain the transparency of the lens, and this homeostasis depends on $\mathrm{Ca}^{2+}$-ATPase pumps. An imbalance of $\mathrm{Ca}^{2+}$ homeostasis is harmful to cells. Increasing intracellular $\mathrm{Ca}^{2+}$ concentrations can cause human lens opacification $(51,52)$. Moreover, UVB irradiation can interfere with $\mathrm{Ca}^{2+}$ signaling of HLECs in vitro, resulting in the apoptosis of target cells (53). In the present study, UVB-induced apoptosis was investigated by flow cytometry, and the expression of the apoptotic proteins, Bad, Bcl-2 and caspase-12, suggested that UVB-induced apoptotic signals may be involved in changes in the $\mathrm{Ca}^{2+}$ concentration.

$\mathrm{Ca}^{2+}$ regulates a number of cellular functions, including cell proliferation, differentiation and death $(54,55) . \mathrm{Ca}^{2+}$ plays an important role in apoptosis, and the increased intracellular $\mathrm{Ca}^{2+}$ concentration has been shown to activate apoptotic pathways $(56,57)$. Increased intracellular $\mathrm{Ca}^{2+}$ levels trigger the activation of caspase-12, leading to apoptosis $(58,59)$. In the present study, to determine the effect of UVB on $\mathrm{Ca}^{2+}$ homeostasis in SRA01/04 cells, control SRA01/04 cells, cells overexpressing Calb1, and cells subjected to the siRNA-mediated knockdown of Calb1 were irradiated with UVB; intracellular $\mathrm{Ca}^{2+}$ levels were then observed to assess the effect of UVB on apoptosis and its association with the concentration of intracellular $\mathrm{Ca}^{2+}$. In addition, the endoplasmic reticulum (ER) plays an important role in maintaining intracellular $\mathrm{Ca}^{2+}$ homeostasis. UVB-induced apoptosis may result in ER stress, which is mediated by the mitochondria $(60,61)$. The increased in intracellular $\mathrm{Ca}^{2+}$ levels induced by UVB irradiation may be closely related to the change in Calb1 expression and the increase in ER stress.

Calb1 is a high-affinity calcium-binding protein widely expressed in the kidneys, pancreas, brain, bone and lens (28). It is the main target of 1,25-dihydroxyvitamin D3, which mainly promotes extracellular $\mathrm{Ca}^{2+}$ transport. Calb1 expression was synchronized with the expression of calcium channels in epithelial cells (62). It exerts a protective effect on nerve cells, among other cell types, where it plays a role in the regulation of apoptosis $(63,64)$. Exogenous Calb1 expression can reduce oxidative stress and maintain mitochondrial function. Nerve cells overexpressing Calb1 have been shown to exhibit a low rate of apoptosis in vitro (65). Calb1 can also protect kidney cells from PT-induced apoptosis and cytotoxicity (66). A number of studies have suggested that the upregulation of intracellular Calb1 expression can reduce the apoptosis induced by different pro-apoptotic pathways.

The present study confirmed that the expression of Calb1 inhibited the UVB-induced apoptosis of HLECs. Calb1 overexpression exerted a protective effect on UVB-induced apoptosis and significantly reduced the expression of Bad and caspase-12. In addition, using siRNA to knockdown Calb1 expression in SRA01/04 cells significantly decreased the survival rate of SRA01/04 cells exposed to UVB radiation; additionally, under these conditions, the protein expression of Bad and caspase- 12 was significantly increased, and the protein expression of Bcl-2 was significantly downregulated.

In conclusion, the present study demonstrates that UVB irradiation can increase intracellular $\mathrm{Ca}^{2+}$ levels directly and/or inhibit $\mathrm{Ca}^{2+}$-ATPase activity and thus disrupt intracellular $\mathrm{Ca}^{2+}$ homeostasis. The UVB radiation-induced apoptosis of SRA01/04 cells may be involved in complex mechanisms, including imbalances in $\mathrm{Ca}^{2+}$ homeostasis. Calb1 protects HLECs from apoptosis by regulating the concentration of intracellular $\mathrm{Ca}^{2+}$, which mediates the expression of the pro-apoptotic proteins, Bad, Bcl-2 and caspase-12.

\section{Acknowledgements}

\section{Not applicable.}

\section{Funding}

The present study was supported by the National Natural Science Foundation of China (grant no. 81560160) grant funded by the Chinese government.

\section{Availability of data and materials}

All data generated or analyzed during this study are included in this published article or are available from the corresponding author on reasonable request. 


\section{Authors' contributions}

$\mathrm{KL}$, as the first author, contributed to the experimental design, the drafting of the manuscript and the analysis and interpretation of the data for the study. JZ is responsible for designing the flow cytometry in ensuring that questions related to the accuracy or integrity had been resolved. LYa completed the cell culture experiments and transfection, and is accountable for all aspects of this part of the study. MG designed and is responsible for the western blot analysis experiments and the relevant data acquisition. LYu designed and was responsible for the collection of cellular morphological research data. YG is the correspondence author and contributed to the experimental conception and design, the statistical analysis of data, the critical revision of the manuscript and the final approval of the manuscript to be published. All authors have read and approved the final manuscript.

\section{Ethics approval and consent to participate}

Not applicable.

\section{Patient consent for publication}

Not applicable.

\section{Competing interests}

The authors declare that they have no competing interests.

\section{References}

1. Jia S, Shi J, Chen X and Tang L: Ultraviolet radiation-induced apoptosis in human lens epithelial cells and its effect on Bcl-2 and Bax. Zhong Nan Da Xue Xue Bao Yi Xue Ban 37: 730-736, 2012 (In Chinese).

2. McCarty CA and Taylor HR: A review of the epidemiologic evidence linking ultraviolet radiation and cataracts. Dev Ophthalmol 35: 21-31, 2002.

3. Li WC, Kuszak JR, Dunn K, Wang RR, Ma W, Wang GM Spector A, Leib M, Cotliar AM and Weiss M: Lens epithelial cell apoptosis appears to be a common cellular basis for non-congenital cataract development in humans and animals. J Cell Biol 130: 169-181, 1995.

4. Andley UP, Walsh A, Kochevar IE and Reddan JR: Effect of ultraviolet-B radiation on protein synthesis in cultured lens epithelial cells. Curr Eye Res 9: 1099-1106, 1990.

5. Andley UP, Malone JP and Townsend RR: Inhibition of lens photodamage by UV-absorbing contact lenses. Invest Ophthalmol Vis Sci 52: 8330-8341, 2011.

6. Lee DH, Cho KS, Park SG, Kim EK and Joo CK: Cellular death mediated by nuclear factor kappa B (NF-kappaB) translocation in cultured human lens epithelial cells after ultraviolet-B irradiation. J Cataract Refract Surg 31: 614-619, 2005.

7. Yao J, Liu Y, Wang X, Shen Y, Yuan S, Wan Y and Jiang Q UVB radiation induces human lens epithelial cell migration via NADPH oxidase-mediated generation of reactive oxygen species and up-regulation of matrix metalloproteinases. Int $\mathbf{J}$ Mol Med 24: 153-159, 2009.

8. Miyashita H, Hatsusaka N, Shibuya E, Mita N, Yamazaki M, Shibata T, Ishida H, Ukai Y, Kubo E and Sasaki H: Association between ultraviolet radiation exposure dose and cataract in Han people living in China and Taiwan: A cross-sectional study. PLoS One 14: e0215338, 2019.

9. Lofgren S: Solar ultraviolet radiation cataract. Exp Eye Res 156: 112-116, 2017.

10. Galichanin K, Lofgren S and Soderberg P: Cataract after repeated daily in vivo exposure to ultraviolet radiation. Health Phys 107: 523-529, 2014.
11. Zhang J, Yan H, Lofgren S, Tian X and Lou MF: Ultraviolet radiation-induced cataract in mice: The effect of age and the potential biochemical mechanism. Invest Ophthalmol Vis Sci 53: 7276-7285, 2012.

12. Mody VC Jr, Kakar M, Elfving A, Soderberg PG and Lofgren S: Ultraviolet radiation-B-induced cataract in albino rats: Maximum tolerable dose and ascorbate consumption. Acta Ophthalmol Scand 84: 390-395, 2006

13. West SK, Longstreth JD, Munoz BE, Pitcher HM and Duncan DD: Model of risk of cortical cataract in the US population with exposure to increased ultraviolet radiation due to stratospheric ozone depletion. Am J Epidemiol 162: 1080-1088, 2005.

14. Midelfart A: Ultraviolet radiation and cataract. Acta Ophthalmol Scand 83: 642-644, 2005.

15. Jing L, Kumari S, Mendelev N and Li PA: Coenzyme q10 ameliorates ultraviolet $\mathrm{B}$ irradiation induced cell death through inhibition of mitochondrial intrinsic cell death pathway. Int J Mol Sci 12: 8302-8315, 2011

16. Shui YB, Sasaki H, Pan JH, Hata I, Kojima M, Yamada Y, Hirai KI, Takahashia N and Sasaki K: Morphological observation on cell death and phagocytosis induced by ultraviolet irradiation in a cultured human lens epithelial cell line. Exp Eye Res 71: 609-618, 2000.

17. Mendelev N, Witherspoon S and Li PA: Overexpression of human selenoprotein $\mathrm{H}$ in neuronal cells ameliorates ultraviolet irradiation-induced damage by modulating cell signaling pathways. Exp Neurol 220: 328-334, 2009.

18. Ricci JE, Gottlieb RA and Green DR: Caspase-Mediated loss of mitochondrial function and generation of reactive oxygen species during apoptosis. J Cell Biol 160: 65-75, 2003.

19. Celio MR: Calbindin D-28k and parvalbumin in the rat nervous system. Neuroscience 35: 375-475, 1990.

20. Persechini A, Moncrief ND and Kretsinger RH: The EF-hand family of calcium-modulated proteins. Trends Neurosci 12: 462-467, 1989.

21. Hemmingsen C: Regulation of renal calbindin-D28k. Pharmacol Toxicol 87 (Suppl 3): S5-S30, 2000.

22. Duncan MJ and Franklin KM: Expression of 5-HT7 receptor mRNA in the hamster brain: Effect of aging and association with calbindin-D28K expression. Brain Res 1143: 70-77, 2007.

23. Iacopino AM, Rhoten WB and Christakos S: Calcium binding protein (calbindin-D28k) gene expression in the developing and aging mouse cerebellum. Brain Res Mol Brain Res 8: 283-290, 1990.

24. Hall AK and Norman AW: Acute actions of 1,25-dihydroxyvitamin D3 upon chick pancreatic calbindin-D28K. Biochem Biophys Res Commun 176: 1057-1061, 1991.

25. Margolis DS, Kim D, Szivek JA, Lai LW and Lien YH: Functionally improved bone in calbindin-D28k knockout mice. Bone 39: 477-484, 2006.

26. Faucheux C, Bareille R and Amedee J: Synthesis of calbindin-D28K during mineralization in human bone marrow stromal cells. Biochemical J 333: 817-823, 1998.

27. Baimbridge KG, Celio MR and Rogers JH: Calcium-Binding proteins in the nervous system. Trends Neurosci 15: 303-308, 1992.

28. Geng Y, Lin HT, Chen W, Liu ZC, Xiang W and Chen WR: Age-Related reduction in calbindin-D28K expression in the sprague-dawley rat lens. Mol Med Rep 11: 422-426, 2015.

29. Ahmadian SS, Rezvanian A, Peterson M, Weintraub S, Bigio EH, Mesulam MM and Geula C: Loss of calbindin-D28K is associated with the full range of tangle pathology within basal forebrain cholinergic neurons in Alzheimer's disease. Neurobiol Aging 36: 3163-3170, 2015.

30. Wang C, Jiang C, Yuan H, Xiao C and Gao D: Role of calbindin-D28K in estrogen treatment for Parkinson's disease. Neural Regen Res 8: 702-707, 2013.

31. Ferrante RJ, Kowall NW and Richardson EP Jr: Proliferative and degenerative changes in striatal spiny neurons in Huntington's disease: A combined study using the section-golgi method and calbindin D28k immunocytochemistry. J Neurosci 11: 3877-3887, 1991.

32. Kiyama H, Seto-Ohshima A and Emson PC: Calbindin D28K as a marker for the degeneration of the striatonigral pathway in Huntington's disease. Brain Res 525: 209-214, 1990.

33. Hong SM, Chung SY, Park MS, Huh YB, Park MS and Yeo SG: Immunoreactivity of calcium-binding proteins in the central auditory nervous system of aged rats. J Korean Neurosurg Soc 45: 231-235, 2009. 
34. Fan Y, Shi L, Gu Y, Zhao Y, Xie J, Qiao J, Yang GY, Wang Y and Lu CZ: Pretreatment with PTD-calbindin D 28k alleviates rat brain injury induced by ischemia and reperfusion. $\mathrm{J}$ Cereb Blood Flow Metab 27: 719-728, 2007.

35. D'Orlando C, Celio MR and Schwaller B: Calretinin and calbindin D-28k, but not parvalbumin protect against glutamate-induced delayed excitotoxicity in transfected N18-RE 105 neuroblastoma-retina hybrid cells. Brain Res 945: 181-190, 2002.

36. Meier TJ, Ho DY, Park TS and Sapolsky RM: Gene transfer of calbindin D28k cDNA via herpes simplex virus amplicon vector decreases cytoplasmic calcium ion response and enhances neuronal survival following glutamatergic challenge but not following cyanide. J Neurochem 71: 1013-1023, 1998.

37. Bellido T, Huening M, Raval-Pandya M, Manolagas SC and Christakos S: Calbindin-D28k is expressed in osteoblastic cells and suppresses their apoptosis by inhibiting caspase-3 activity. J Biol Chem 275: 26328-26332, 2000.

38. Youn HY, McCanna DJ, Sivak JG and Jones LW: In vitro ultraviolet-induced damage in human corneal, lens, and retinal pigment epithelial cells. Mol Vis 17: 237-246, 2011.

39. Okuno T: Ultraviolet action spectrum for cell killing in a human lens epithelial cell line. Ind Health 45: 137-142, 2007.

40. Teng H, Huang LY, Tian F, Dong LJ and Zhang H: Effects of SMP-30 overexpression on apoptosis of human lens epithelial cells induced by ultraviolet B irradiation. Zhonghua Yan Ke Za Zhi 53: 835-841, 2017 (In Chinese; Abstract available in Chinese from the publisher).

41. Li WC and Spector A: Lens epithelial cell apoptosis is an early event in the development of UVB-induced cataract. Free Radic Biol Med 20: 301-311, 1996.

42. Sun X, Zou W and Zhao C: Expression of P53 during lens epithelial cell apoptosis induced by ultraviolet. J Tongji Med Univ 21: 263-264, 2001.

43. Andley UP, Lewis RM, Reddan JR and Kochevar IE: Action spectrum for cytotoxicity in the UVA- and UVB-wavelength region in cultured lens epithelial cells. Invest Ophthalmol Vis Sci 35: 367-373, 1994.

44. Marian MJ, Li H, Borchman D and Paterson CA: Plasma membrane $\mathrm{Ca} 2+-\mathrm{ATPase}$ expression in the human lens. Exp Eye Res 81: 57-64, 2005.

45. Marian MJ, Mukhopadhyay P, Borchman D, Tang D and Paterson CA: Regulation of sarco/endoplasmic and plasma membrane calcium ATPase gene expression by calcium in cultured human lens epithelial cells. Cell Calcium 41: 87-95, 2007.

46. Wu Q, Guo D, Bi H, Wang D and Du Y: UVB irradiation-induced dysregulation of plasma membrane calcium ATPase1 and intracellular calcium homeostasis in human lens epithelial cells. Mol Cell Biochem 382: 263-272, 2013.

47. Williams MR, Duncan G, Riach RA and Webb SF: Acetylcholine receptors are coupled to mobilization of intracellular calcium cultured human lens cells. Exp Eye Res 57: 381-384, 1993.

48. Riach RA, Duncan G, Williams MR and Webb SF: Histamine and ATP mobilize calcium by activation of $\mathrm{H} 1$ and $\mathrm{P} 2 \mathrm{u}$ receptors in human lens epithelial cells. J Physiol 486: 273-282, 1995.

49. Masaki H, Izutsu Y, Yahagi S and Okano Y: Reactive oxygen species in HaCaT keratinocytes after UVB irradiation are triggered by intracellular $\mathrm{Ca}(2+)$ levels. J Investig Dermatol Symp Proc 14: 50-52, 2009.

50. Ding BX and Wang CB: Inhibitory effect of polypeptides from chlamys farreri on UVB-induced apoptosis and DNA damage in normal human dermal fibroblasts in vitro. Acta Pharmacol Sin 24: 1006-1010, 2003

51. Wackernagel W, Ettinger K, Weitgasser U, Bakir BG, Schmut O, Goessler W and Faschinger C: Opacification of a silicone intraocular lens caused by calcium deposits on the optic. J Cataract Refract Surg 30: 517-520, 2004.
52. Truscott RJ, Marcantonio JM, Tomlinson J and Duncan G: Calcium-induced opacification and proteolysis in the intact rat lens. Invest Ophthalmol Vis Sci 31: 2405-2411, 1990.

53. Hightower KR, Duncan G, Dawson A, Wormstone IM, Reddan J and Dziedizc D: Ultraviolet irradiation (UVB) interrupts calcium cell signaling in lens epithelial cells. Photochem Photobiol 69: 595-598, 1999.

54. Dolmetsch RE, Lewis RS, Goodnow CC and Healy JI: Differential activation of transcription factors induced by $\mathrm{Ca} 2+$ response amplitude and duration. Nature 386: 855-858, 1997.

55. Richter $\mathrm{C}$ and Kass GE: Oxidative stress in mitochondria: It relationship to cellular $\mathrm{Ca} 2+$ homeostasis, cell death, proliferation, and differentiation. Chem Biol Interact 77: 1-23, 1991.

56. Martikainen P, Kyprianou N, Tucker RW and Isaacs JT: Programmed death of nonproliferating androgen-independent prostatic cancer cells. Cancer Res 51: 4693-4700, 1991.

57. Lynch K, Fernandez G, Pappalardo A and Peluso JJ: Basic fibroblast growth factor inhibits apoptosis of spontaneously immortalized granulosa cells by regulating intracellular free calcium levels through a protein kinase Cdelta-dependent pathway. Endocrinology 141: 4209-4217, 2000.

58. Huang Y, Li X, Wang Y, Wang H, Huang C and Li J: Endoplasmic reticulum stress-induced hepatic stellate cell apoptosis through calcium-mediated JNK/P38 MAPK and Calpain/Caspase-12 pathways. Mol Cell Biochem 394: 1-12, 2014.

59. Li L, Cao Z, Jia P and Wang Z: Calcium signals and caspase-12 participated in paraoxon-induced apoptosis in EL4 cells. Toxicol In Vitro 24: 728-736, 2010.

60. Jiang L, Liu Y, Ma MM, Tang YB, Zhou JG and Guan YY: Mitochondria dependent pathway is involved in the protective effect of bestrophin-3 on hydrogen peroxide-induced apoptosis in basilar artery smooth muscle cells. Apoptosis 18: 556-565, 2013.

61. Min SK, Lee SK, Park JS, Lee J, Paeng JY, Lee SI, Lee HJ, Kim Y, Pae HO, Lee SK and Kim EC: Endoplasmic reticulum stress is involved in hydrogen peroxide induced apoptosis in immortalized and malignant human oral keratinocytes. J Oral Pathol Med 37: 490-498, 2008.

62. Hoenderop JG, Hartog A, Stuiver M, Doucet A, Willems PH and Bindels RJ: Localization of the epithelial $\mathrm{Ca}(2+)$ channel in rabbit kidney and intestine. J Am Soc Nephrol 11: 1171-1178, 2000.

63. Sun S, Li F, Gao X, Zhu Y, Chen J, Zhu X, Yuan H and Gao D: Calbindin-D28K inhibits apoptosis in dopaminergic neurons by activation of the PI3-kinase-Akt signaling pathway. Neuroscience 199: 359-367, 2011.

64. Verdes JM, Morana JA, Battes D, Gutiérrez F, Guerrero F, Goicoa A, Fidalgo LE, Barbeito CG, Zanuzzi CN, Portiansky EL and Gimeno EJ: Calbindin D28k expression and the absence of apoptosis in the cerebellum of solanum bonariense L-intoxicated bovines. Vet Pathol 47: 569-572, 2010.

65. Guo Q, Christakos S, Robinson N and Mattson MP: Calbindin D28k blocks the proapoptotic actions of mutant presenilin 1: Reduced oxidative stress and preserved mitochondrial function. Proc Natl Acad Sci USA 95: 3227-3232, 1998.

66. Turner PR, Mefford S, Christakos S and Nissenson RA: Apoptosis mediated by activation of the $\mathrm{G}$ protein-coupled receptor for parathyroid hormone (PTH)/PTH-related protein (PTHrP). Mol Endocrinol 14: 241-254, 2000.

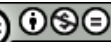

This work is licensed under a Creative Commons Attribution-NonCommercial-NoDerivatives 4.0 International (CC BY-NC-ND 4.0) License. 